\title{
TOTAL PHENOLIC CONTENT AND FREE RADICAL SCAVENGING ACTIVITY OF REPRESENTATIVE MEDICINAL PLANTS OF THAILAND
}

\section{CHAIYAVAT CHAIYASUT T ${ }^{1}$, PERIYANAINA KESIKA ${ }^{1}$, KHONTAROS CHAIYASUT $^{2,3}$, PIYANUT SITTIYUNO $^{1}$, SARTJIN PEERAJAN ${ }^{2}$, BHAGAVATHI SUNDARAM SIVAMARUTHI ${ }^{1 *}$}

${ }^{1}$ Innovation Center for Holistic Health, Nutraceuticals and Cosmeceuticals, Faculty of Pharmacy, Chiang Mai University, Chiang Mai 50200, Thailand, Asia. ${ }^{2}$ Health Innovation Institute, Chiang Mai 50230, Thailand, Asia. ${ }^{3}$ Institute of Research and Development, Chiang Mai Rajabhat University, Chiang Mai 50300, Thailand, Asia. Email: sivasgene@gmail.com

Received: 15 June 2017, Revised and Accepted: 20 July 2017

\section{ABSTRACT}

Objective: Plants are the vital source of pharmaceutically important compounds with less or no adverse side effects. The current study was conducted to catalog the commonly used indigenous and medicinal plants of Thailand based on their phenolic acid content and antioxidant activity.

Methods: The herbs were collected from Chiang Mai province, Thailand. The plants were extracted with 70\% ethanol. The total phenolic acid content and antioxidant activity were evaluated.

Results: The ethanolic extract of plant samples was prepared. Among the tested plant samples, Phyllanthus emblica Linn. and Terminalia belerica Roxb. showed highest phenolic content (Gallic acid equivalent [GAE]; $764.81 \mathrm{mg}$ GAE/g sample) and antioxidant activity (trolox equivalent antioxidant capacity [TEAC]; $394.20 \mathrm{mg} / \mathrm{g}$ sample), respectively. About 94-97\% of inhibition of free radical was detected in 2,2-diphenyl-1-picrylhydrazyl (DPPH) assay tested against the plant samples. The ethanolic extract of Anaxagorea luzonensis Gray., Terminalia sp., T. belerica Roxb, Terminalia chebula Retz., Albizia procera Benth., Harrisonia perforata Merr., and P. emblica Linn. exhibited 97.87, 96.08, 92.26, 86.74, 86.08, 84.47, and 83.13\% of superoxide radical inhibition, respectively.

Conclusion: The results suggested that T. belerica Roxb. possessed high TEAC ability and DPPH radical scavenging capacity and A. luzonensis Gray. exhibited high superoxide scavenging activity, when compared to that of the other tested samples. The additional detailed study is desirable to understand the complexity and distribution of bioactive compounds present in the commonly used plant species of Thailand.

Keywords: Antioxidant activity, Ethanolic extract, Phenolic acids, Thai plants.

(C) 2017 The Authors. Published by Innovare Academic Sciences Pvt Ltd. This is an open access article under the CC BY license (http://creativecommons. org/licenses/by/4. 0/) DOI: http://dx.doi.org/10.22159/ajpcr.2017.v10i11.20741

\section{INTRODUCTION}

Plants are the rich source of vitamins, minerals, and other essential nutrients. Most of the plants have a medicinal property which is attributed to the high content of phenolic acids, flavonoids, and other phytochemicals. The use of plant and plant derivatives as medicine for the prevention and treatment of several diseases is recorded for thousands of years, and it is the ancient practice to cure the diseases. The key mechanism of healing ability of the medicinal plant and its phytochemicals is free radical scavenging activity.

Numerous studies have reported the medicinal uses of several plant species $[1,2]$. The antioxidant ability of Indian medicinal herbs has been reviewed. Some of the plants such as Amaranthus paniculatus, Aerva lanata, Coccinia indica, and Coriandrum sativum, which are rich in antioxidant compounds, are used in regular cooking as vegetables showing that these plants could be a source of dietary antioxidants [3]. Krishnaiah et al. [4] reviewed about the antioxidant potential of medicinal plant species such as Pistacia lentiscus, Diospyros abyssinica, Sargentodoxa cuneata Rehd. Et Wils, Crataeva nurvala Buch-Ham., Polyalthia cerasoides (Roxb.) Bedd., Acacia auriculiformis A. Cunn., Momordica charantia L., Rheum ribes L., Teucrium polium L., Urtica dioica L., Bidens pilosa Linn. Radiata, Ficus microcarpa L. fil., Leea indica, Uncaria tomentosa (Willd.) DC, Geranium sanguineum L., Dracocephalum moldavica L., Salvia officinalis L., and Pelargonium endlicherianum. The studies revealed that the natural antioxidants are effective, and side effect-free substitute to synthetic compounds in the functional food productions, as well as in medicine.
Some of the reports explained about the antioxidant activity and antioxidant compounds of edible plants and commonly found plants of Thailand [5,6]. The documentation of antioxidant capacity and other related phytochemical contents of the frequently used plants are essential to explore the naturally available medicinal compounds. Thus, the purpose of this study was to document the total phenolic acid content and antioxidant ability of the most generally used indigenous and medicinal plants of Thailand, collected in the region of Chiang Mai.

\section{METHODS}

Sample collection and extraction

The plant samples were collected at local markets of Chiang Mai, Thailand, and the plant species were confirmed by comparing with the herbarium specimen of Faculty of Pharmacy, Chiang Mai University, Thailand.

The collected plant samples were cleaned with sterile water and smashed into small pieces. About 100-200 g of plant samples were mixed with 400-700 $\mathrm{ml}$ of ethanol:water (7:3) solvent system, and the samples were heated and extracted using Soxhlet extractor. For the indigenous plant samples, the extraction was done without heating step and without using soxhlet extractor. Indigenous plant samples were soaked in prescribed amount of $70 \%$ ethanol for $1 \mathrm{hr}$. Then, the extracts were filtered through Whatman No. 1 filter paper, and the extracts were collected and stored in an amber bottle at $4{ }^{\circ} \mathrm{C}$ until use. 
Total phenolic content

The total phenolic content of the extracted plant samples was determined as described in the previous studies [7], and the total phenolic content was represented as mg of gallic acid equivalent (GAE) (mg GAE) per g of plant extract.

\section{Free radical scavenging activity}

Total antioxidant capacity of the tested plant extracts was evaluated by 2,2'-Azino-bis(3-ethylbenzthiazoline-6-sulfonic acid) (ABTS) assay as described previously [7], and the results were represented as Trolox equivalent antioxidant capacity (TEAC) per g of the plant extract. In addition, the free radical scavenging property of the plant extracts was also evaluated by 2,2-diphenyl-1-picrylhydrazyl (DPPH) assay and superoxide anion radical scavenging assay as detailed previously $[7,8]$. Both DPPH and superoxide anion radical scavenging assay results were represented as a percentage of inhibition. All the samples were tested in triplicate.

\section{Statistical analysis}

The data were represented as mean \pm SD. ANOVA with least significant difference post-hoc test was executed to evaluate the significant differences and $\mathrm{p}<0.05$ was considered to be statistically significant using statistical SPSS software version 16 (Chicago, SPSS Inc., U.S.A)

\section{RESULTS AND DISCUSSION}

The plant samples were collected (Table 1) and the contents were extracted with ethanol:water (7:3 ratio) extraction method. Then, the extracts were subjected to total phenolic acid content analysis by Folin-Ciocalteu method and free radical scavenging activity by ABTS, DPPH, and superoxide anion radical scavenging assays.

The phenolic acid content of the ethanolic extract of the tested plant samples was represented as GAE (mg/g extract). The top 10 plant species with highest GAE values are as follows Phyllanthus emblica
Linn. (764.81 mg/g extract) > Betula alnoides Buch Ham. (620.80 mg/g extract) $>$ Terminalia sp. (506.41 mg/g extract) $>$ Anaxagorea luzonensis Gray. (438.03 mg/g extract) >Terminalia chebula Retz. (389.18 mg/g extract) $>$ Caesalpinia mimosoides Lamk. (234.92 mg/g extract) $>$ Jussiaea repens Linn. (229.41 mg/g extract) >Gymnema inodorum Decne. (83.35 mg/g extract) >Manihot esculenta Crantz. (75.78 mg/g extract) $>$ Ocimum sanctum Linn. (62.39 mg/g extract). The least amount of total phenolic acid content was detected in the ethanolic extract of Spilanthes acmella (Linn.) Murr. (1.41 mg/g extract) (Fig. 1).

The total phenolic content, antioxidant property, antimutagenic, and antibacterial activities of ethanolic extract of $P$. emblica branches were comparable to the ability of $P$. emblica fruits [9]. The polyphenolic content of $P$. emblica fruit was enriched during the fermentation with Lactobacillus paracasei HII01 [10]. T. chebula has been reported to contain gallic acid, ellagic acid, tannic acid (about 30\%), ethyl gallate, chebulic acid, chebulagic acid, corilagin, mannitol, ascorbic acid, and other compounds $[11,12]$. The species of Caesalpinia are accounted for its phytochemical contents and pharmacological importance and are evidently reviewed by Zanin et al. [13].

M. esculenta Crantz. leaves extract was reported for phenols, anthocyanins, and ascorbic acid content with free radical scavenging properties [14]. Coniferaldehyde, isovanillin, 6-deoxyjacareubin, scopoletin, syringaldehyde, pinoresinol, p-coumaric acid, ficusol, balanophonin, and ethamivan are the known antioxidant compounds present in $M$. esculenta Crantz. [15]. About 254.44 TAE/mg of extract of tannin, Vitamin C (1.7-419 mg/100 g), â-carotene (around 23-86 mg/100 g), Vitamin A, saponins, steroids, and glycosides were reported in M. esculenta Crantz. [16-18].

O. sanctum Linn. is made of multiple chemical constituents, and the composition of the phytochemical was varied among the cultivars and affected by the processing, storage, etc., O. sanctum Linn. oil contains

Table 1: List of plants and plant parts collected and used in the study

\begin{tabular}{|c|c|c|c|c|c|}
\hline Sample No. & Indigenous plants & Part used & Sample No. & Medicinal plants & Part used \\
\hline 1 & Ocimum sanctum Linn. & Fresh leaf & 16 & Betula alnoides Buch Ham. & Wood \\
\hline 2 & Caesalpinia mimosoides Lamk. & Apical bud & 17 & Anaxagorea luzonensis Gray. & Stem \\
\hline 3 & Piper sarmentosum Roxb. & Fresh leaf & 18 & Betula alnoides Buch Ham. & Core of stem \\
\hline 4 & Plantago major Linn. & Whole plant & 19 & Streblus asper Lour. & Stem \\
\hline 5 & Monochoria vaginalis Presl. & Fresh leaf & 20 & Harrisonia perforata Merr. & Root \\
\hline 6 & Spilanthes acmella (Linn.) Murr. & Whole plant & 21 & Plumbago indica Linn. & Root \\
\hline 7 & Gymnema inodorum Decne. & Fresh leaf & 22 & Capparis micracantha DC. & Root \\
\hline 9 & Iresine herbstii Hook. & Fresh leaf & 24 & Clerodendrum indicum Kuntze. & Root \\
\hline 10 & Oenanthe javanica DC. & Fresh leaf & 25 & Phyllanthus emblica Linn. & Fruit \\
\hline 11 & Oroxylum indicum Vent. & Root & 26 & Ficus racemosa $\mathrm{L}$. & Fruit \\
\hline 12 & Jussiaea repens Linn. & Fresh leaf & 27 & Tiliacora triandra Diels. & Fresh leaf \\
\hline 13 & Antidesma ghaesembilla Gaertn. & Fruit & 28 & Terminalia chebula Retz. & Dry fruit \\
\hline 14 & Manihot esculenta Crantz. & Apical bud & 29 & Terminalia sp. & Dry fruit \\
\hline 15 & Piper ribesioides & Fresh leaf & 30 & Terminalia belerica Roxb. & Dry fruit \\
\hline
\end{tabular}

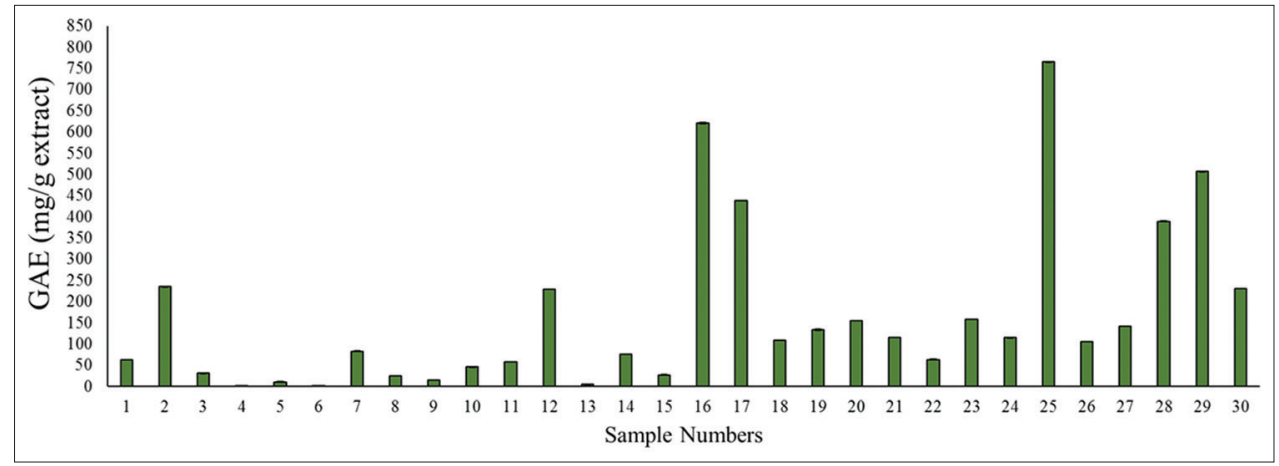

Fig. 1: The total phenolic content (Gallic acid equivalent) of the plant extracts 
eugenol, euginal, ursolic acid, carboxylic acid, carvacrol, linalool, limatrol, caryophyllene, methyl carvicol, fatty acids, and sitosterol. The chemical constituents of $O$. sanctum were detailed clearly by Pattanayak et al. [19].

The current study suggested that P. emblica Linn. had high phenolic content (764.81 mg/g sample) when compared to that of the other tested samples (Fig. 1).

Total antioxidant capacity of the plant extracts was determined and represented as TEAC ( $\mathrm{mg} / \mathrm{g}$ sample). The top 10 plant samples with highest TEAC values are as follows: Terminalia belerica Roxb. (394.20 mg/g extract) >P. emblica Linn. (392.98 mg/g extract) > Terminalia sp. (390.77 mg/g extract) $>$ T. chebula Retz. $(388.95 \mathrm{mg} / \mathrm{g}$ extract) $>$ A. luzonensis Grey. (385.41 mg/g extract) >Caesalpinia mimosoides Lamk. (196.15 mg/g extract) >J. repens Linn. (194.21 mg/g extract) >Polygonum flaccidum Meissn. (190.31 mg/g extract) $>$ Antidesma ghaesembilla Gaertn. (154.72 mg/g extract) >Piper sarmentosum Roxb. (153.56 mg/g extract). The least value of TEAC acid was recorded in the ethanolic extract of Tiliacora triandra Diels. (45.80 mg/g extract) (Fig. 2)

In DPPH assay, about $94-97 \%$ of inhibition was found to be exhibited by the tested plant extracts. More specifically, T. belerica Roxb.

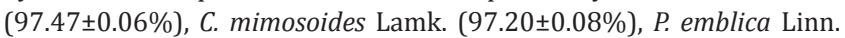
(97.17 $\pm 0.01 \%)$, Terminalia sp., (96.62\%), J. repens Linn. (96.24 $\pm 0.02 \%)$,

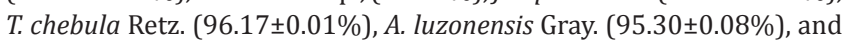
P. flaccidum Meissn. (94.30 $\pm 0.05 \%)$ showed high activity in DPPH assay. Whereas, Streblus asper Lour. (2.98 $\pm 0.37 \%)$, Capparis micracantha DC. (2.62 $\pm 0.26 \%)$, and Monochoria vaginalis Presl. (2.15 $\pm 1.1 \%)$ displayed a non-significant level of activity in DPPH assay (Fig. 3).

The superoxide radical scavenging activity of the tested extracts was determined. The ethanolic extract of $A$. luzonensis Gray., Terminalia sp., T. belerica Roxb., T. chebula Retz., Albizia procera Benth., Harrisonia perforata Merr., and P. emblica Linn. showed 97.87, 96.08, 92.26, 86.74, $86.08,84.47$, and $83.13 \%$ of superoxide radical inhibition, respectively. The minimum superoxide radical inhibition activity was observed in

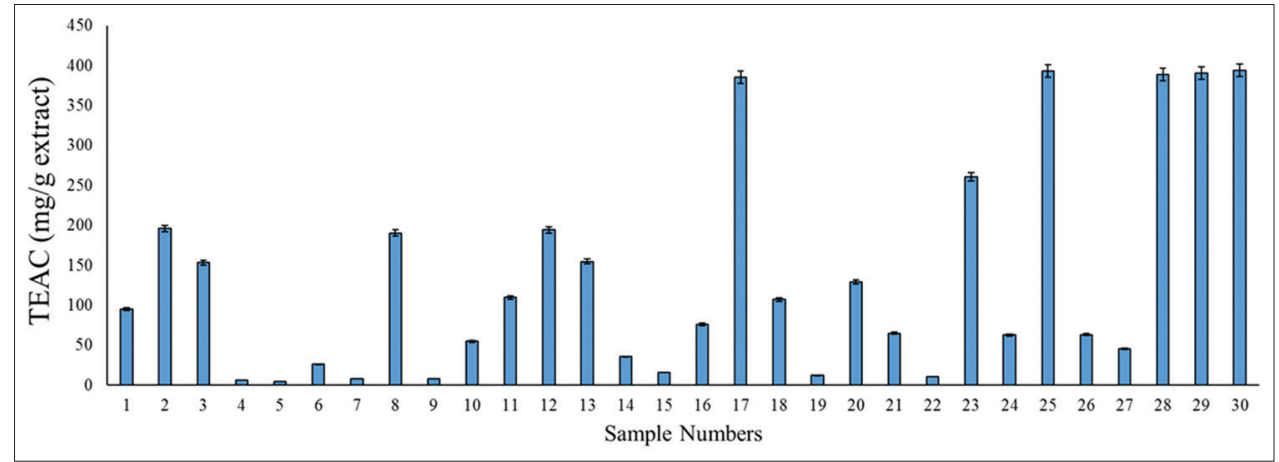

Fig. 2: The antioxidant capacity (trolox equivalent of antioxidant capacity) of the plant extracts

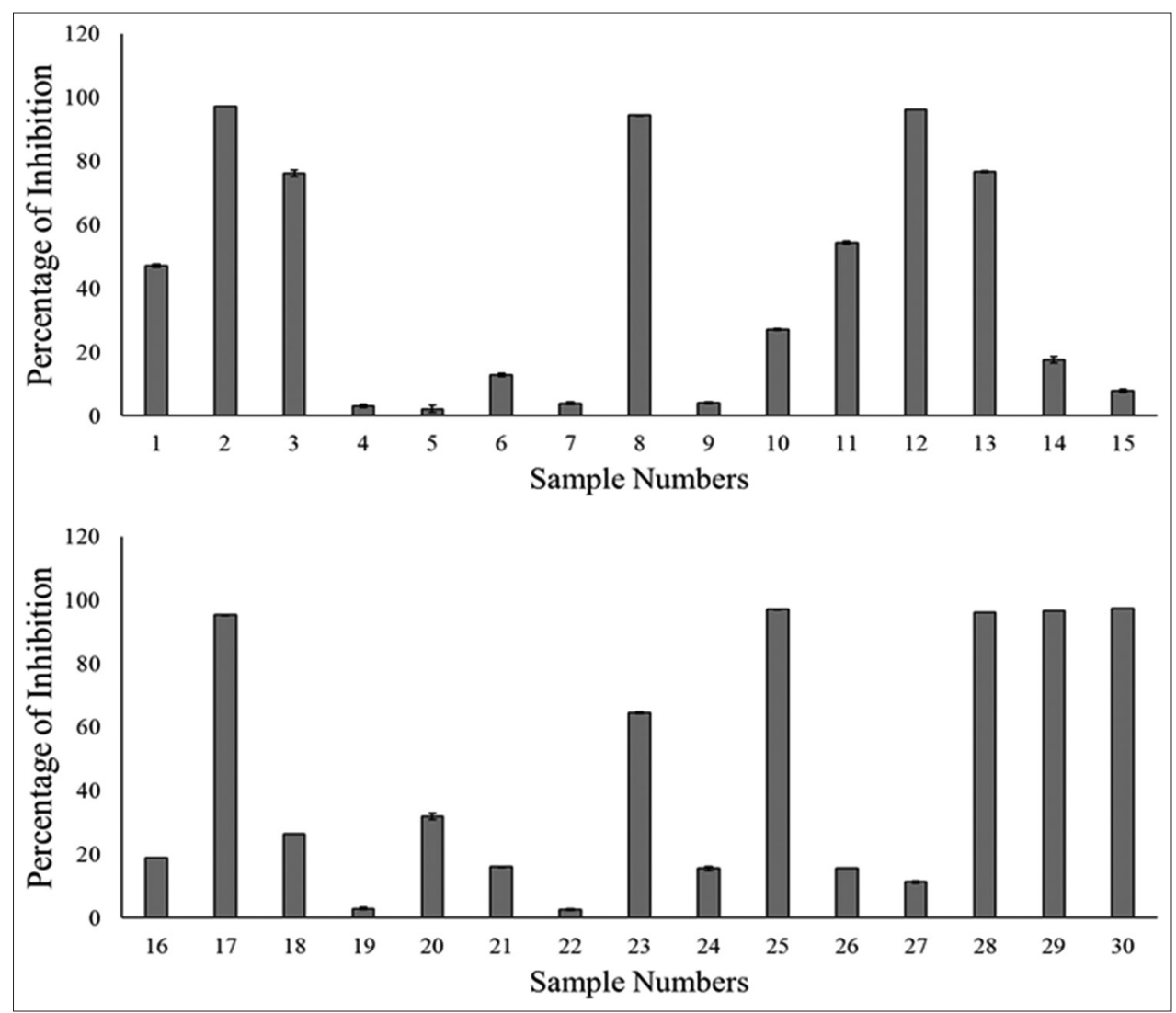

Fig. 3: Percentage of inhibition of free radical by plant extracts in 2,2-diphenyl-1-picrylhydrazyl assay 
Table 2: Categorization of top five potent plant species based on the total phenolic acid content and antioxidant activity

\begin{tabular}{lllll}
\hline Rank & Phenolic content (GAE) & Total antioxidant capacity (TEAC) & \% of inhibition (DPPH assay) & $\begin{array}{l}\text { \% of inhibition (superoxide } \\
\text { radical assay) }\end{array}$ \\
\hline 1 & Phyllanthus emblica Linn. & Terminalia belerica Roxb. & Terminalia belerica Roxb. & Anaxagorea luzonensis Gray. \\
2 & Betula alnoides Buch Ham. & Phyllanthus emblica Linn. & Phyllanthus emblica Linn. & Terminalia sp. \\
3 & Terminalia sp. & Terminalia sp. & Terminalia sp. & Terminalia belerica Roxb. \\
4 & Anaxagorea luzonensis Gray. & Terminalia chebula Retz. & Terminalia chebula Retz. & Terminalia chebula Retz. \\
5 & Terminalia chebula Retz. & Anaxagorea luzonensis Gray. & Anaxagorea luzonensis Gray. & Phyllanthus emblica Linn. \\
\hline GAE: Gallic acid equivalent, TEAC: Trolox equivalent antioxidant capacity, DPPH: 2,2-diphenyl-1-picrylhydrazyl &
\end{tabular}

the M. vaginalis Presl. (4.83\%) and Oenanthe javanica DC. (7.38\%) extract (Fig. 4).

The literature survey suggested that the fruits of $P$. emblica Linn. have been reported for its antioxidant, antipyretic, antimicrobial, anticancer, anti-inflammatory, immunomodulatory, hypolipidemic, and hepatoprotective properties [20-27]. The methanolic extract of P. emblica has been reported for the bacterial efflux pump inhibiting activity [28]. The aqueous extract of $P$. emblica exhibited the antidepressant activity at higher doses in mice [29].

The dried ripe fruit of T. chebula is an essential herb used widely in the indigenous system of medicine for its homeostatic, laxative, antitussive, diuretic, and cardiotonic activities [30].

Caesalpinia sp. extract has antiulcer, anticancer, antidiabetic, antiinflammatory, antimicrobial, and antirheumatic properties [13,31].

The alcoholic extracts of Jussiaea species were stated to have antibacterial, anti-inflammatory, antidiabetic, antidiarrheal, antitumor, antitussive, and antipyretic activities [32]. Ethyl acetate extract of aerial parts of $J$. repens was non-toxic and exhibited antioxidant, anti-inflammatory, hepatoprotective, and antidiabetic activities [32]. G. inodorum has been reported for hypoglycemic effect in healthy human [33].

M. esculenta Crantz. has been used to treat fever, diarrhea, headache, rheumatism conjunctivitis, abscess, demulcent, hypertension, marasmus, irritable bowel syndrome, aches, antiseptic, cyanogenetic, diuretic, dysentery, flu, prostatitis, snake bites, and spasms [34,35]. An in vivo study conducted by Bahekar and Kale [30] also suggested that G. inodorum was a reliable source of plant antioxidant.

O. sanctum Linn. is known as vitalizer and increases physical endurance. The in vivo hypoglycemic, hypolipidemic, and antioxidant properties of $O$. sanctum were evaluated and reported [36]. A full pharmacological importance of $O$. sanctum has been reviewed by Pattanayak et al. [19]. O. sanctum is used in the siddha medicine for the treatment of nephrotic disorders $[37,38]$

The current study also evidences the antioxidant properties of the selected plant samples. The data indicated that T. belerica Roxb. exhibited high TEAC ability and DPPH-based free radical scavenging capacity and A. luzonensis Gray. showed high superoxide scavenging activity when compared to that of the other tested samples (Figs. 2-4). The best 5 plants were categorized based on the GAE, TEAC, and antioxidant activity, which are assessed in this study, and are tabulated in Table 2.

\section{CONCLUSION}

The current study results conclude that T. belerica Roxb. was a potent source of antioxidant compounds compared to other tested samples. Moreover, the study estimates only the phenolic content of the plant sample. Other than phenolic acids, other phytochemicals are responsible for the free radical scavenging activity, which was demonstrated in the study. For example, $P$. emblica had high GAE score but reduced superoxide activity compared to the that of the other plant samples. Nevertheless, the extraction methods also influence the

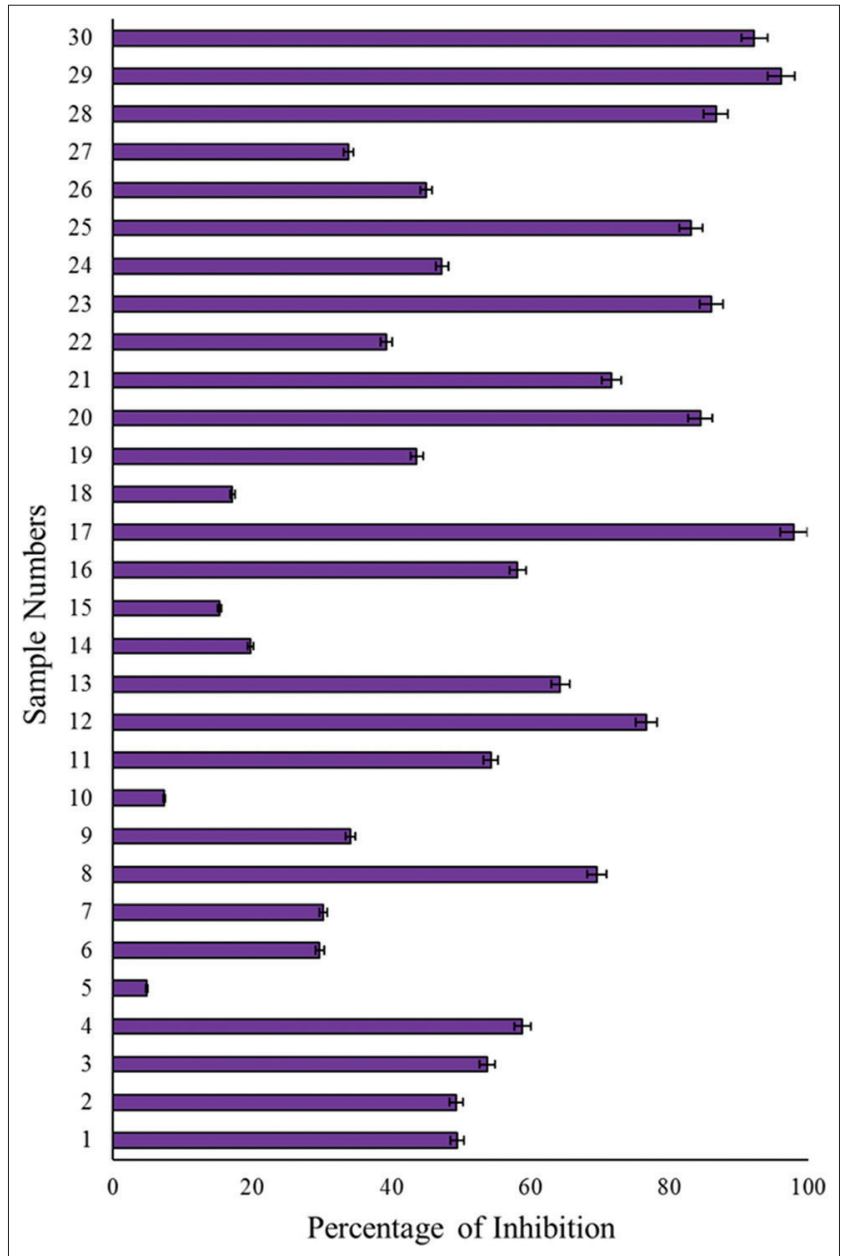

Fig. 4: Percentage of inhibition of superoxide radical by plant extracts

phytochemical content and the bioactivity. Thus, the further detailed study is needed to understand the complexity and distribution of bioactive compounds present in the commonly used plant species of Thailand that can be used to improve nutraceutical or cosmetic product with plant antioxidants.

\section{ACKNOWLEDGMENT}

Authors would like to acknowledge Chiang Mai University grant (CMUgrant) for the support. Authors also gratefully acknowledge the Faculty of Pharmacy, and Chiang Mai University, Thailand, for the support and instrumentation facilities.

\section{REFERENCES}

1. Scartezzini P, Speroni E. Review on some plants of Indian traditional medicine with antioxidant activity. J Ethnopharmacol 2000;71(12):23-43. 
2. Matkowski A. Plant in vitro culture for the production of antioxidants-a review. Biotechnol Adv 2008;26(6):548-60.

3. Ali SS, Kasoju N, Luthra A, Singh A, Sharanabasava H, Sahu A, et al. Indian medicinal herbs as sources of antioxidants. Food Res Int 2008;41:1-15.

4. Krishnaiah D, Sarbatly R, Nithyanandam R. A review of the antioxidant potential of medicinal plant species. Food Bioprod Process 2011;89:217-33.

5. Chanwitheesuk A, Teerawutgulrag A, Rakariyatham N. Screening of antioxidant activity and antioxidant compounds of some edible plants of Thailand. Food Chem 2005;92:491-7.

6. Tachakittirungrod S, Okonogi S, Chowwanapoonpohn S. Study on antioxidant activity of certain plants in Thailand: Mechanism of antioxidant action of guava leaf extract. Food Chem 2007;103:381-8.

7. Pengkumsri N, Chaiyasut C, Saenjum C, Sirilun S, Peerajan S, Suwannalert $\mathrm{P}$, et al. Physicochemical and antioxidative properties of black, brown and red rice varieties of northern Thailand. Food Sci Technol (Campinas) 2015;35(2):331-8

8. Chaiyasut C, Sivamaruthi BS, Pengkumsri N, Sirilun S, Peerajan S, Chaiyasut K, et al. Anthocyanin profile and its antioxidant activity of widely used fruits, vegetables, and flowers in Thailand. Asian J Pharm Clin Res 2016;9(6):218-24.

9. Sripanidkulchai B, Fangkrathok N. Antioxidant, ant mutagenic and antibacterial activities of extracts from Phyllanthus emblica branches. Songklanakarin J Sci Technol 2014;36(6):669-74

10. Peerajan S, Chaiyasut C, Sirilun S, Chaiyasut K, Kesika P, Sivamaruthi BS. Enrichment of nutritional value of Phyllanthus emblica fruit juice using the probiotic bacterium, Lactobacillus paracasei HII01 mediated fermentation. Food Sci Technol (Campinas) 2016;36(1):116-23.

11. Grover IS, Bala S. Antimutagenic activity of Terminalia chebula (myroblan) in Salmonella typhimurium. Indian J Exp Biol 1992;30(4):339-41.

12. Chattopadhyay RR, Bhattacharyya SK. Plant review Terminalia chebula: An update. Pharmacogn Rev 2007;1(1):151-6.

13. Zanin JL, de Carvalho BA, Martineli PS, dos Santos MH, Lago JH, Sartorelli $\mathrm{P}$, et al. The genus Caesalpinia L. (Caesalpiniaceae): Phytochemical and pharmacological characteristics. Molecules 2012;17(7):7887-902.

14. Suresh R, Saravanakumar M, Suganyadev P. Anthocyanins from Indian cassava (Manihot esculenta Crantz) and its antioxidant properties. Int J Pharm Sci Res 2011;2:1819-28.

15. Yi B, Hu L, Mei W, Zhou K, Wang H, Luo Y, et al. Antioxidant phenolic compounds of cassava (Manihot esculenta) from Hainan. Molecules 2011;16(12):10157-67.

16. Fasuyi AO. Nutrient composition and processing effects on cassava Leaf (Manihot esculenta crantz) ant nutrients. Pak J Nutr 2005;4:37-42.

17. Okeke CU, Iweala E. Antioxidant profile of Dioscorea rotundata, Manihot esculenta, Ipoemea batatas, Vernonia amygdalina and Aloe vera. J Med Res Technol 2007;4:4-10.

18. Al-Rofaai A, Rahman WA, Sulaiman SF, Yahaya ZS. In vitro ovicidal and larvicidal activity of methanolic leaf extract of Manihot esculenta (cassava) on susceptible and resistant strains of Trichostrongylus colubriformis. Vet Parasitol 2012;190(1-2):127-35.

19. Pattanayak P, Behera P, Das D, Panda SK. Ocimum sanctum Linn. A reservoir plant for therapeutic applications: An overview. Pharmacogn Rev 2010;4(7):95-105.

20. Liu X, Zhao M, Wang J, Yang B, Jiang Y. Antioxidant activity of methanolic extract of Emblica fruit (Phyllanthus emblica L.) from six regions in China. J Food Comp Anal 2008;21:219-28.
21. Gupta M, Shaw BP, Mukherjee A. Evaluation of antipyretic effect of a traditional polyherbal preparation: A double-blind, randomized clinical trial. Int J Pharm 2008;4:190-5.

22. Sultana S, Ahmed S, Jahangir T. Emblica officinalis and hepatocarcinogenesis: A chemopreventive study in Wistar rats. J Ethnopharmacol 2008;118(1):1-6.

23. Rahman S, Akbor MM, Howlader A, Jabbar A. Antimicrobial and cytotoxic activity of the alkaloids of Amlaki (Emblica officinalis). Pak J Biol Sci 2009;12(16):1152-5.

24. Dang GK, Parekar RR, Kamat SK, Scindia AM, Rege NN. Antiinflammatory activity of Phyllanthus emblica, Plumbago zeylanica and Cyperus rotundus in acute models of inflammation. Phytother Res 2011;25(6):904-8.

25. Liu X, Zhao M, Wu K, Chai X, Yu H, Tao Z, et al. Immunomodulatory and anticancer activities of phenolics from emblica fruit (Phyllanthus emblica L.). Food Chem 2012;131:685-90.

26. Nain P, Saini V, Sharma S, Nain J. Antidiabetic and antioxidant potential of Emblica officinalis Gaertn. Leaves extract in streptozotocininduced Type-2 diabetes mellitus (T2DM) rats. J Ethnopharmacol 2012;142(1):65-71.

27. Thakur RS, Ahirwar BA. Ethnopharmacological evaluation of medicinal plants for cytotoxicity against various cancer cell lines. Int J Pharm Pharm Sci 2017;9(5):198-202.

28. Mehta J, Jandaik S, Urmila. Evaluation of phytochemicals and synergistic interaction between plant extracts and antibiotics for efflux pump inhibitory activity against Salmonella enterica serovar Typhimurium strains. Int J Pharm Pharm Sci 2016;8(10):217-23.

29. Dattatray BP, Padmaja AM, Nirmala NR. Antidepressant activity of aqueous extracts of fruits of Terminalia chebula and Phyllanthus emblica in behavioral models of depression: Involvement of monoaminergic system. Int J Pharm Pharm Sci 2014;6(8):615-20.

30. Bahekar SE, Kale RS. Evaluation of antioxidant activity of Manihot esculenta Crantz in Wistar rats. J Pharm Bioallied Sci 2016;8(2):119-23.

31. Tangsaengvit N, Kitphati W, Tadtong S, Bunyapraphatsara N, Nukoolkarn V. Neurite outgrowth and neuroprotective effects of quercetin from Caesalpinia mimosoides Lamk. On cultured P19-derived neurons. Evid Based Complement Alternat Med 2013;2013:838051.

32. Marzouk MS, Soliman FM, Shehata IA, Rabee M, Fawzy GA. Flavonoids and biological activities of Jussiaea repens. Nat Prod Res 2007;21(5):436-43.

33. Chiabchalard A, Tencomnao T, Santiyanont R. Effect of Gymnema inodorum on postprandial peak plasma glucose levels in healthy human. Afr J Biotechnol 2010;9(7):1079-85.

34. Tsumbu CN, Deby-Dupont G, Tits M, Angenot L, Franck T, Serteyn D, et al. Antioxidant and antiradical activities of Manihot esculenta Crantz (Euphorbiaceae) leaves and other selected tropical green vegetables investigated on lip peroxidation and phorbol-12-myristate-13-acetate (PMA) activated monocytes. Nutrients 2011;3:818-38.

35. Abd-Aziz SM, Low CN, Chai LC, Abd-Razak SS, Selamat J, Son R, et al. Screening of selected Malaysian plants against several food borne pathogen bacteria. Int Food Res J 2011;18:1195-201.

36. Hussain EH, Jamil K, Rao M. Hypoglycaemic, hypolipidemic and antioxidant properties of tulsi (Ocimum sanctum Linn) on streptozotocin induced diabetes in rats. Indian J Clin Biochem 2001;16(2):190-4.

37. Yang HC, Zuo Y, Fogo AB. Models of chronic kidney disease. Drug Discov Today Dis Models 2010;7(1-2):13-19.

38. Maurya H, Kumar T. A review on comprehensive overview in the management of nephrotic disorders. J Crit Rev 2016;3(2):34-43. 